\title{
The effect of demineralization on the physicochemical and sorption properties of activated bio-carbons
}

\author{
Aleksandra Bazan-Wozniak ${ }^{1} \cdot$ Piotr Nowicki $^{1} \cdot$ Robert Pietrzak $^{1}$ (D)
}

Received: 28 November 2018 / Revised: 29 December 2018 / Accepted: 3 January 2019 / Published online: 24 January 2019

(c) The Author(s) 2019, corrected publication 2019

\begin{abstract}
Residues after supercritical extraction of hops were chosen as activated bio-carbons precursor. The actual adsorbent was prepared by physical activation of the starting material. Some amount of the activated bio-carbon was divided into two parts. One of them was washed with distilled water, while the other part of the activated bio-carbon was washed first with a 5\% solution of $\mathrm{HCl}$ and then with distilled water. The activated bio-carbons obtained were subjected to textural characterization and determination of $\mathrm{pH}$ and the content of surface oxygen groups. Carbonaceous adsorbents obtained were tested for removal of gas pollutant of acidic character (nitrogen dioxide) and liquid organic (methylene blue) and inorganic (iodine) pollutants. The maximum sorption capacity of the carbonaceous adsorbents towards iodine was $1395 \mathrm{mg} / \mathrm{g}$, while towards methylene blue it was $238 \mathrm{mg} / \mathrm{g}$. The results have shown that physical activation of the residue after supercritical extraction of hops is possible to be used as precursor of activated bio-carbons showing high adsorption capacity towards nitrogen dioxide reaching a maximum of $72.1 \mathrm{mg} / \mathrm{g}$. The effectiveness of nitrogen dioxide removal depends on bio-carbons preparation and the conditions of adsorption.
\end{abstract}

Keywords Hops · Activated bio-carbons $\cdot$ Physical activation $\cdot$ Adsorption $\cdot$ Nitrogen dioxide $\cdot$ Methylene blue

\section{Introduction}

Pollution of the natural environment is a global threat to life and it has been continuously increasing (Jones et al. 2015; Pallarés et al. 2018). The increase in air and water pollution is directly related to growing urbanization and industrialization (Kuramochi et al. 2012). One of the most effective methods of pollutants removal is adsorption, which is a nontoxic and very effective process (Rafatullah et al. 2010; Bazan et al. 2016; Benedetti et al. 2018). This realization has stimulated the search for new effective adsorbents showing high adsorption capacity, high selectivity and low cost of production (Bulut and Baysal 2006; Nowicki et al. 2016). Activated carbons that have been most often applied as adsorbents of pollutants from liquid and gas phases show a number of attractive physicochemical properties that would characterize the optimum adsorbent (Georgin et al. 2016; Bashkova and Bandosz 2009). According to literature data,

Robert Pietrzak

pietrob@amu.edu.pl

1 Faculty of Chemistry, Adam Mickiewicz University in Poznań, Umultowska 89b, 61-614 Poznań, Poland carbon materials can be obtained by chemical or physical activation of not only the well-known precursors such as wood, fossil coal or peat, but also all kinds of post-agricultural and post-industrial waste products (Benaddi et al. 2000; Bazan-Wozniak et al. 2017; Koyuncu et al. 2018). This fact is very important from the ecological and economic aspects as the growing amount of waste and stringent regulations on protection of the natural environment stimulate the search for methods of their utilization.

A large group of waste materials are the residues of supercritical extraction of plants. The extraction is applied to obtain fatty acids, ethereal oils and aromas used in cosmetic industry and perfume production (Capuzzo et al. 2013; del Valle 2015; Millao and Uquiche 2016).

The aim of this study was to obtain activated bio-carbons by physical activation of residues of supercritical extraction of hops. The sorbents obtained were tested in the process of removal of gas pollutants of acidic character, including nitrogen dioxide, and liquid pollutants such as iodine and methylene blue. 


\section{Materials and methods}

\subsection{Precursor and activated bio-carbons preparation}

The residue left after supercritical extraction of hops obtained from New Chemical Synthesis Institute, Supercritical Extraction Department, Puławy, Poland, was used as the precursor in this study. The starting material was powder with grain size range of $0.10-0.80 \mathrm{~mm}$ and moisture content in air-dry state of $5.6 \mathrm{wt} \%$. The precursor was at first subjected to pyrolysis process in a traditional resistance pipe furnace at $500{ }^{\circ} \mathrm{C}$. The residue was heated $10{ }^{\circ} \mathrm{C} / \mathrm{min}$ from room temperature to the final pyrolysis temperature, kept for $1 \mathrm{~h}$ and then it was cooled in an inert atmosphere. Pyrolysis product was next subjected to physical activation with carbon dioxide. Physical activation of bio-char was carried out at temperature of $800{ }^{\circ} \mathrm{C}$ under a stream of carbon dioxide with a flow rate of $0.250 \mathrm{~L} / \mathrm{min}$, for $1 \mathrm{~h}$. The activated bio-carbon obtained was labeled as P. Next, the final product of activation was divided into two parts. One of them was washed distilled water (P1) while the second part of the activated bio-carbon (P2) was subjected to demineralization with $\mathrm{HCl}$. In order to do this the activated bio-carbon was placed in a round-bottom flask and flooded with a $5 \% \mathrm{HCl}$ solution. The flask was equipped with a reflux, then the contents of the flask were heated to the boiling point and kept at this temperature for $3 \mathrm{~h}$. After this time the contents were poured out onto a funnel heater and washed with warm distilled water until free of chloride ions. The washed materials were dried at $110{ }^{\circ} \mathrm{C}$ for $24 \mathrm{~h}$.

\subsection{Sample characterization}

For all activated bio-carbons the ash content was determined according to the ASTM D2866-94 Standard (2004).

Characterization of the porous structure of obtained materials was performed on the grounds of low temperature nitrogen adsorption-desorption isotherms measured on Autosorb iQ at $-196{ }^{\circ} \mathrm{C}$. Surface area of activated bio-carbons was calculated by Brunauer-Emmett-Teller method and total pore volume and size distribution according to Barrett-Joyner-Halenda method. Furthermore micropore volume and micropore area were determined using t-plot method.

The content of surface oxygen functional groups was determined according to the Boehm method (Boehm 1994). A portion of $0.25 \mathrm{~g}$ of bio-carbon sample was placed in $25 \mathrm{~mL}$ of $0.1 \mathrm{~mol} / \mathrm{L}$ solutions of either sodium hydroxide or hydrochloric acid. The vials were sealed and shaken for $24 \mathrm{~h}$ and then $10 \mathrm{~mL}$ of each filtrate was pipetted and the excess of base or acid was titrated with $0.1 \mathrm{~mol} / \mathrm{L} \mathrm{HCl}$ or $\mathrm{NaOH}$, as required. The numbers of acidic sites of various types were calculated assuming that $\mathrm{NaOH}$ neutralizes all acidic groups and $\mathrm{HCl}$ reacts with all basic group. All experiments were made twice.

\subsection{Adsorption of iodine and methylene blue}

The iodine sorption ability of the adsorbents was determined according to the following procedure: Portions of $0.2 \mathrm{~g}$ of the samples sieved to a particle size below $1 \mathrm{~mm}$ were placed in $250 \mathrm{~mL}$ flasks and $4 \mathrm{~mL}$ of $5 \% \mathrm{HCl}$ was added. Then $20 \mathrm{~mL}$ of stock $0.2 \mathrm{~mol} / \mathrm{L}$ iodine solution was added to it and the mixture was shaken for $4 \mathrm{~min}$ in a shaker. All the samples were filtered through filter paper and next washed with $50 \mathrm{~mL}$ of water. The resulting solution was titrated with $0.1 \mathrm{~mol} / \mathrm{L}$ sodium thiosulphate $(1 \%$ starch solution was used as an indicator) until the solution become colorless.

Adsorption of methylene blue was performed using the following procedure. Samples of the prepared bio-carbons of $0.025 \mathrm{~g}$ with the particle size of $0.09 \mathrm{~mm}$ were added to $50 \mathrm{~mL}$ of dye solution with initial concentrations in the range from 10 to $130 \mathrm{mg} / \mathrm{L}$ and the suspension was stirred to reach equilibrium for $24 \mathrm{~h}$. After the adsorption equilibrium had been achieved, the solution was separated from the sorbent by centrifugation at $6000 \mathrm{rpm}$, for $10 \mathrm{~min}$. The concentration of dye solution was determined using double beam UV-Vis spectrophotometer (Carry $100 \mathrm{Bio}$ ) at $665 \mathrm{~nm}$. The equilibrium adsorption capacities $\mathrm{q}_{\mathrm{e}}(\mathrm{mg} / \mathrm{g})$ were calculated according to the following formula:

$q_{\mathrm{e}}=\frac{\left(C_{0}-C_{\mathrm{e}}\right)}{m} \times V$

where in $C_{0}$ is the initial concentration $(\mathrm{mg} / \mathrm{L}), C_{e}$ is the residual concentration $(\mathrm{mg} / \mathrm{L}), V$ is the volume of the solution $(\mathrm{L}), m$ is the mass of the adsorbent $(\mathrm{g})$.

\section{$2.4 \mathrm{NO}_{2}$ adsorption experiments}

Sorption capacities of the samples towards nitrogen dioxide were evaluated with the use of an electrochemical sensor for monitoring gas concentration made by QREA PLUS (model PGM-2000). The activated bio-carbon in the amount of $3 \mathrm{~mL}$ was placed in a glass reactor and through the adsorbent bed a mixture of air and nitrogen dioxide was passed. The proportions of air and $\mathrm{NO}_{2}$ were chosen so that the $\mathrm{NO}_{2}$ concentration was $1000 \mathrm{ppm}$. The flow rate of $\mathrm{NO}_{2}$ was $90 \mathrm{~mL} / \mathrm{min}$, while the flow rate of air was $360 \mathrm{~mL} / \mathrm{min}$. The concentration of $\mathrm{NO}_{2}$ was measured in real time and expressed in ppm, up to the value of $20 \mathrm{ppm}$ (max. limit of the sensor). The process of adsorption was carried out in 
dry (D) or wet (W, 70\% humidity) conditions. After the end of adsorption the rate of $\mathrm{NO}_{2}$ desorption from the adsorbent bed was measured (Nowicki et al. 2012). Additionally to check the $\mathrm{NO}_{2}$ reduction as a result of its reaction with surface oxygen groups or carbon matrix, the concentration of NO in the system was also monitored till $200 \mathrm{ppm}$.

\section{Results and discussion}

\subsection{Characterization of the activated bio-carbons}

According to the data from Fig. 1, the ash content in the activated bio-carbons obtained from residues of supercritical extraction of hops varies from 5.3 to $32.2 \mathrm{wt} \%$. The highest ash content was in sample P. High content of mineral substance in the structure of this coal does not eliminate its potential use as adsorbent of gas phase pollutants, as has been demonstrated by our earlier studies (Bazan et al. 2016), however, it should be taken into account that ash components may block some pores in the activated carbon structure, thus reducing their surface area. That is why we introduced the process of washing of the carbon material with a $5 \% \mathrm{HCl}$ solution and/ or distilled water. Sample P1, washed only with distilled water, has a half reduced content of ash $16 \mathrm{wt} \%$ than sample P. On the other hand, sample $\mathrm{P} 2$, washed with $\mathrm{HCl}$ solution and distilled water, has over

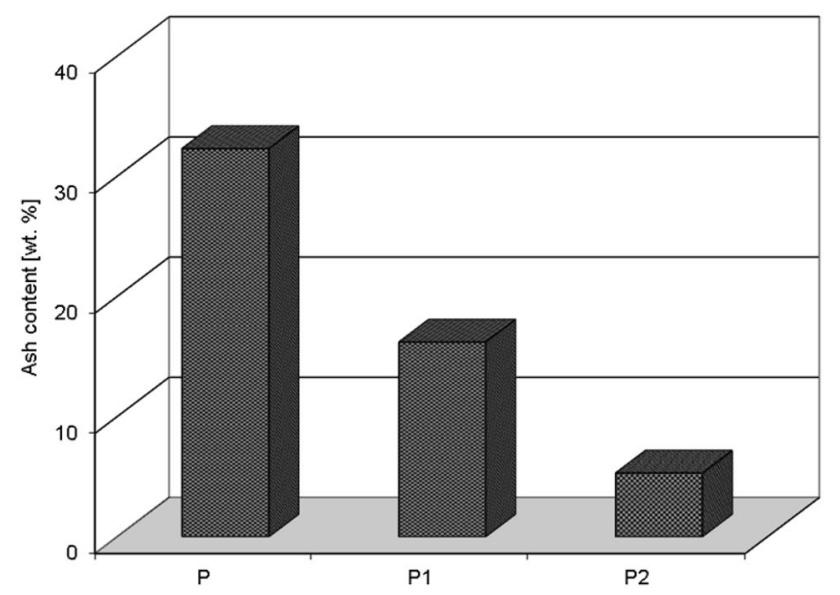

Fig. 1 Ash content of the activated bio-carbons sixfold lower content of ash than bio-carbon $\mathrm{P}$ and threefold lower content of ash than sample P1.

Table 1 presents the textural parameters characterizing the carbon materials obtained from the nitrogen adsorption/ desorption isotherms. Bio-carbon $\mathrm{P} 2$ shows the most developed surface area and porous structure and is the only sample whose $\mathrm{S}_{\mathrm{BET}}$ exceeds $1000 \mathrm{~m}^{2} / \mathrm{g}$. The surface area of the bio-carbons obtained depends significantly on the variant of sample washing after activation. According to the data from Table 1, the sorbent washing with distilled water leads to an increase in the surface area by over $200 \mathrm{~m}^{2} / \mathrm{g}$ (P1-664 $\mathrm{m}^{2} / \mathrm{g}$ ), while the washing of bio-carbon samples first with $\mathrm{HCl}$ solution than with distilled water leads to over twice increase in the surface area $\left(\mathrm{P} 2-1013 \mathrm{~m}^{2} / \mathrm{g}\right)$ with respect to that of the unwashed sample $\left(\mathrm{P}-413 \mathrm{~m}^{2} / \mathrm{g}\right)$. Washing with $\mathrm{HCl}$ causes unblocking of pores in the biocarbon structure and improves its textural properties.

As follows from Table 1, bio-carbon P shows the most microporous character as the micropores make as much as $70 \%$ of its total pore volume. In samples P1 and P2 the contribution of micropores is much smaller as they make about $45 \%$ of their pore volume. The mean pore diameters in the bio-carbons studied range from 3.55 to $4.10 \mathrm{~nm}$, which indicates the presence of mesopores in these samples.

In order to establish the acid-base properties of the biocarbons obtained, the contents of surface oxygen functional groups of acidic and basic character were estimated and $\mathrm{pH}$ of the water extracts were determined. The total content of oxygen functional groups in the samples varies from 2.99 to $4.87 \mathrm{mmol} / \mathrm{g}$, while the $\mathrm{pH}$ of their water extracts varies from 4.6 to 10.8. It is evident from the data presented in Table 2 that the surfaces of samples $\mathrm{P}$ and $\mathrm{P} 1$ show basic character. The $\mathrm{pH}$ values of their water extracts range from 8.6 to 10.8 and the content of oxygen functional groups of acidic nature is small (sample P) or they do not occur at all

Table 2 Acid-base properties of the activated bio-carbons obtained

\begin{tabular}{lrll}
\hline Sample & $\mathrm{pH}$ & $\begin{array}{l}\text { Acidic groups } \\
(\mathrm{mmol} / \mathrm{g})\end{array}$ & $\begin{array}{l}\text { Basic } \\
\text { groups } \\
(\mathrm{mmol} / \mathrm{g})\end{array}$ \\
\hline $\mathrm{P}$ & 10.8 & 0.00 & 4.87 \\
$\mathrm{P} 1$ & 8.6 & 0.00 & 4.39 \\
$\mathrm{P} 2$ & 4.6 & 1.44 & 0.55 \\
\hline
\end{tabular}

Table 1 Textural parameters of the activated bio-carbons obtained

\begin{tabular}{llllll}
\hline Sample & $\begin{array}{l}\text { Surface area } \\
\left(\mathrm{m}^{2} / \mathrm{g}\right)\end{array}$ & $\begin{array}{l}\text { Micropore area } \\
\left(\mathrm{m}^{2} / \mathrm{g}\right)\end{array}$ & $\begin{array}{l}\text { Total pore volume } \\
\left(\mathrm{cm}^{3} / \mathrm{g}\right)\end{array}$ & $\begin{array}{l}\text { Micropore volume } \\
\left(\mathrm{cm}^{3} / \mathrm{g}\right)\end{array}$ & $\begin{array}{l}\text { Average pore } \\
\text { diameter }(\mathrm{nm})\end{array}$ \\
\hline $\mathrm{P}$ & 413 & 329 & 0.20 & 0.14 & 3.92 \\
$\mathrm{P} 1$ & 664 & 376 & 0.36 & 0.16 & 3.55 \\
$\mathrm{P} 2$ & 1039 & 645 & 0.60 & 0.27 & 4.10 \\
\hline
\end{tabular}




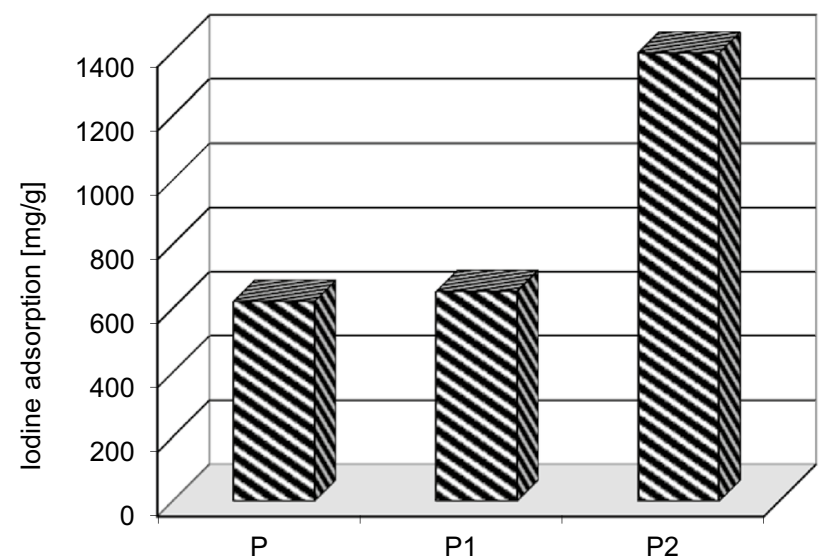

Fig. 2 Adsorption of iodine on the activated bio-carbons

(sample P1). The type of functional groups and their number depend significantly on the type of washing procedure. Washing of sample P1 with distilled water causes an insignificant decrease in the number of functional groups of basic nature relative to their number on the surface of bio-carbon $\mathrm{P}$. The washing at first with $\mathrm{HCl}$ solution and then with distilled water favors generation of acidic functional groups so in bio-carbon $\mathrm{P} 2$ the number of basic functional groups decreased. Sample P2 has the surface of acidic character as evidenced by predominance of acidic functional groups and $\mathrm{pH}$ values of water extract from this sample of 4.6. So drastic change in the acid-base characteristics follows from the fact that $\mathrm{HCl}$ removes a considerable amount of mineral substance from the carbon samples and the mineral substance has usually basic nature.

\subsection{Adsorption of iodine and methylene blue}

The obtained bio-carbons were tested for the removal of two model pollutants: iodine and methylene blue, from liquid phase. The results are presented in Figs. 2 and 3. The effectiveness of adsorption of iodine and methylene blue from water solutions by the activated bio-carbons depends on the variant of their obtaining and their textural parameters. The most effective adsorbent of both pollutants proved to be sample P2 as it was able to adsorb $1395 \mathrm{mg}$ of iodine and $238 \mathrm{mg}$ of methylene blue. So high sorption capacity was most probably a consequence of much developed surface area and the porous structure of this bio-carbon. The lowest sorption capacity towards both pollutants showed sample $\mathrm{P}$, obtained by physical activation of the residue of supercritical extraction of hops, characterized by the poorest textural parameters. Bio-carbon $\mathrm{P}$ has a high content of mineral substance that can block the adsorbate particles access to the adsorbent surface (Kazmierczak et al. 2013).

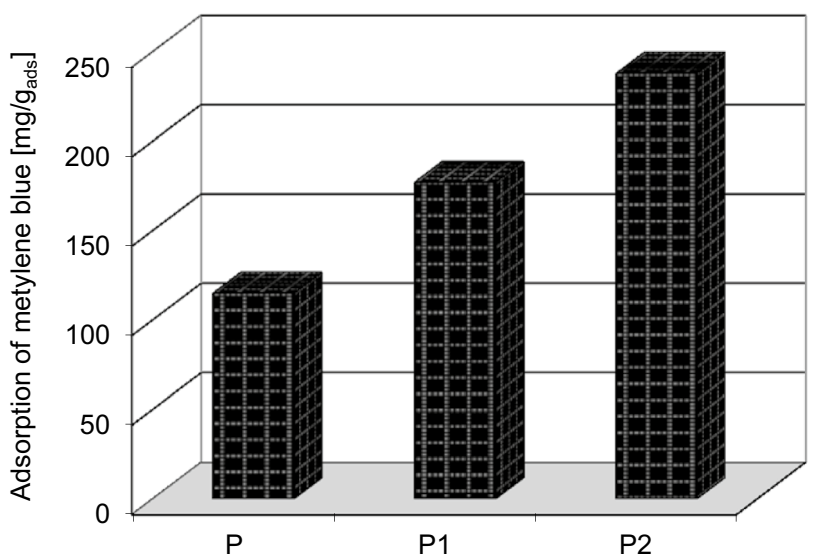

Fig. 3 Adsorption of methylene blue on the activated bio-carbons

Table 3 Comparison of iodine and methylene blue adsorption for activated bio-carbons prepared from hops and commercial carbons $(\mathrm{mg} / \mathrm{g})$

\begin{tabular}{llll}
\hline Sample & Iodine & Methylene blue & References \\
\hline P & 622 & 115 & This study \\
P1 & 653 & 177 & This study \\
P2 & 1395 & 238 & This study \\
Norit SX2 & Min. 800 & 150 & $\begin{array}{c}\text { Kulikowska and Sułek } \\
(2008)\end{array}$ \\
& & & Nowicki et al. (2015) \\
CWZ-22 & Min. 750 & 130 & Nowicki et al. (2015) \\
WG-12 & 1050 & 180 & \\
\hline
\end{tabular}

Table $4 \quad \mathrm{NO}_{2}$ breakthrough capacities of the activated biocarbons obtained

\begin{tabular}{lll}
\hline Sample & \multicolumn{2}{l}{$\begin{array}{l}\text { Conditions } \\
(\mathrm{mg} / \mathrm{g})\end{array}$} \\
\cline { 2 - 3 } & Dry & Wet \\
\hline P & 42.0 & 72.1 \\
P1 & 36.7 & 58.0 \\
P2 & 10.0 & 24.4 \\
\hline
\end{tabular}

Table 3 presents the sorption capacities towards iodine and methylene blue obtained for the bio-carbons obtained from residues of supercritical extraction of hops and for the commercial adsorbents. As follows from a comparison of these data, the bio-carbons obtained from hops (in particular sample P2) have sorption capacities similar to those of the commercial materials obtained from peat (Norit SX2), charcoal (CWZ-22) and low-ash coking coal (WG-12).

\subsection{Adsorption of nitrogen dioxide}

Table 4 presents the sorption capacities of the activated biocarbons studied towards $\mathrm{NO}_{2}$. The effectiveness of removal of this toxic gas depends considerably on the conditions of 
adsorption. For all activated bio-carbons the sorption capacities towards $\mathrm{NO}_{2}$ were higher when adsorption took place in the presence of steam. This observation can be explained by the formation of water film on the activated bio-carbons surfaces, which favors binding of nitrogen dioxide. The effect of test conditions on the sorption capacities towards $\mathrm{NO}_{2}$ was the least pronounced for sample P2.

The highest sorption capacity towards $\mathrm{NO}_{2}$ showed sample $\mathrm{P}$, whose sorption capacity was $42.0 \mathrm{mg}$ in dry conditions and $72.1 \mathrm{mg}$ in wet conditions. Activated bio-carbon $\mathrm{P}$ has a relatively high content of mineral substance (Fig. 1), whose presence may be conducive to adsorption of gas pollutants such as nitrogen dioxide (Bazan et al. 2016). The other two samples, washed with $5 \%$ water solution of $\mathrm{HCl}$ and/ or distilled water showed much lower sorption capacities towards $\mathrm{NO}_{2}$. It should be mentioned that the highest effectiveness of $\mathrm{NO}_{2}$ removal by sample $\mathrm{P}$ is beneficial from the ecological and economic points of view as washing is related to additional cost and use of large volumes of water.

In order to get more information of the processes taking place in the activated carbon upon $\mathrm{NO}_{2}$ adsorption, Fig. 4 presents the curves illustrating changes in $\mathrm{NO}_{2}$ upon adsorption in dry and wet conditions. Only small differences between the samples can be noted, which suggests that the process of $\mathrm{NO}_{2}$ removal for the samples studied takes place according to the same [similar] mechanism. For all samples the concentration of $\mathrm{NO}_{2}$ was equal to zero for a certain period of time and only after the breakthrough a gradual increase in $\mathrm{NO}_{2}$ concentration was observed. Comparison of the curves recorded upon $\mathrm{NO}_{2}$ adsorption reveals that when the process is run in the presence of steam (Fig. 4b) the period of time throughout which $\mathrm{NO}_{2}$ concentration is zero is longer. This observation confirms the beneficial effect of steam on the sorption capacities. Further analysis shows that after cessation of $\mathrm{NO} 2$ inflow to the adsorbent bed, for all samples adsorbing in dry conditions and for bio-carbon $\mathrm{P}$ in wet conditions, a rapid decrease in $\mathrm{NO}_{2}$ concentration to $0 \mathrm{ppm}$ takes place, which may indicate that the majority of adsorbed $\mathrm{NO}_{2}$ is strongly bound in the porous structure or has undergone chemisorption. Only for bio-carbons P1 and $\mathrm{P} 2$ (in wet conditions) the concentration of $\mathrm{NO}_{2}$ remains at a level of 2 ppm after $30 \mathrm{~min}$ of the adsorbent bed washing with a stream of fresh air.

Figure $5 \mathrm{a}, \mathrm{b}$ present the curves of NO concentration changes, illustrating the $\mathrm{NO}_{2}$ reduction to $\mathrm{NO}$ on the surface of bio-carbons studied. The effectiveness of reduction depends first of all on the variant of adsorption. The highest reduction potential, both in dry and wet conditions, showed sample P2. For this sample upon adsorption in dry conditions the maximum NO possible to be measured with the electrochemical sensor used, of $200 \mathrm{ppm}$, was reached in $5 \mathrm{~min}$, while in wet conditions in about $10 \mathrm{~min}$ from the beginning of the adsorption test. The least intensive was the process of reduction of nitrogen dioxide to nitrogen monoxide for sample $\mathrm{P}$, not subjected to washing after activation. However, it should be taken into account that the reduction of $\mathrm{NO}_{2}$ to $\mathrm{NO}$ is disadvantageous from the ecological point of view so further studies should be concentrated on its restriction or elimination.

\section{Conclusions}

On the basis of the results of our study it can be concluded that the activated bio-carbons obtained from the residues of supercritical extraction of hops can be successfully applied as effective adsorbents for removal of pollutants from liquid and gas phases. Effectiveness of removal of iodine and
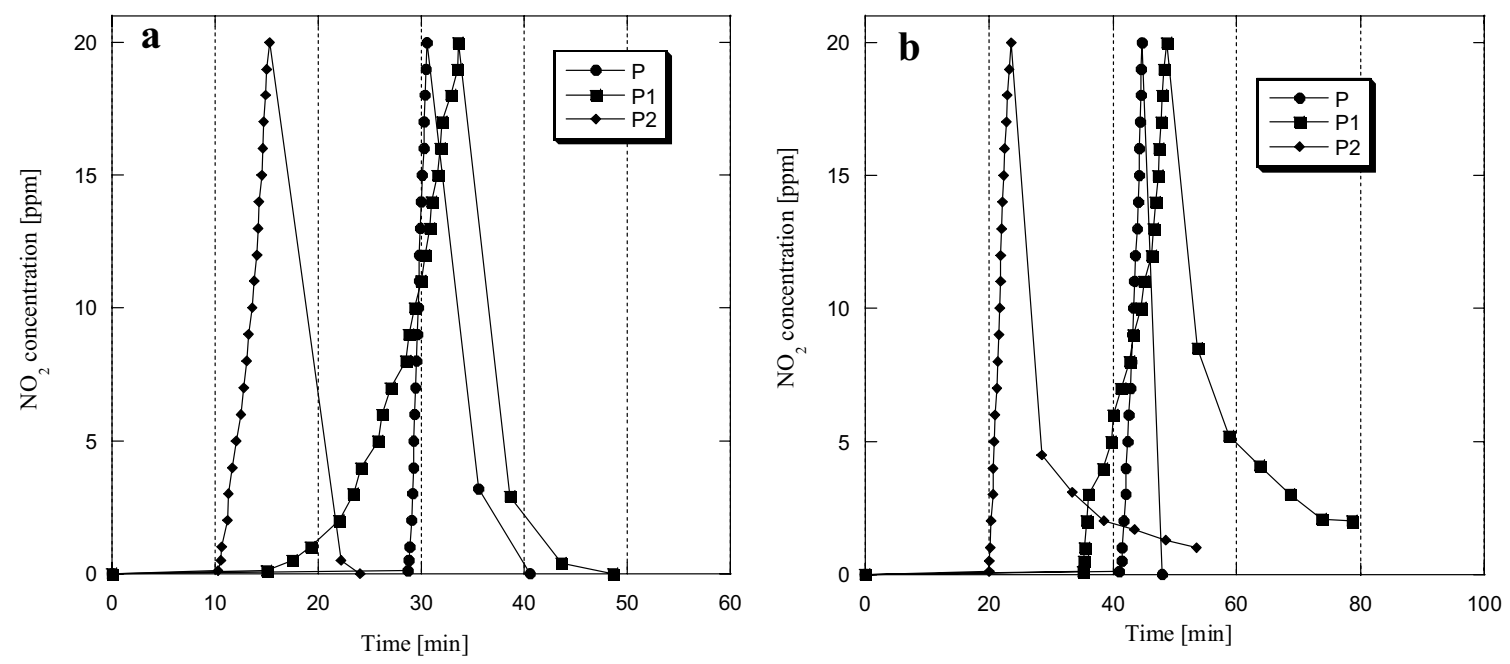

Fig. $4 \mathrm{NO}_{2}$ breakthrough curves for the activated bio-carbons studied in dry (a) and wet (b) conditions 

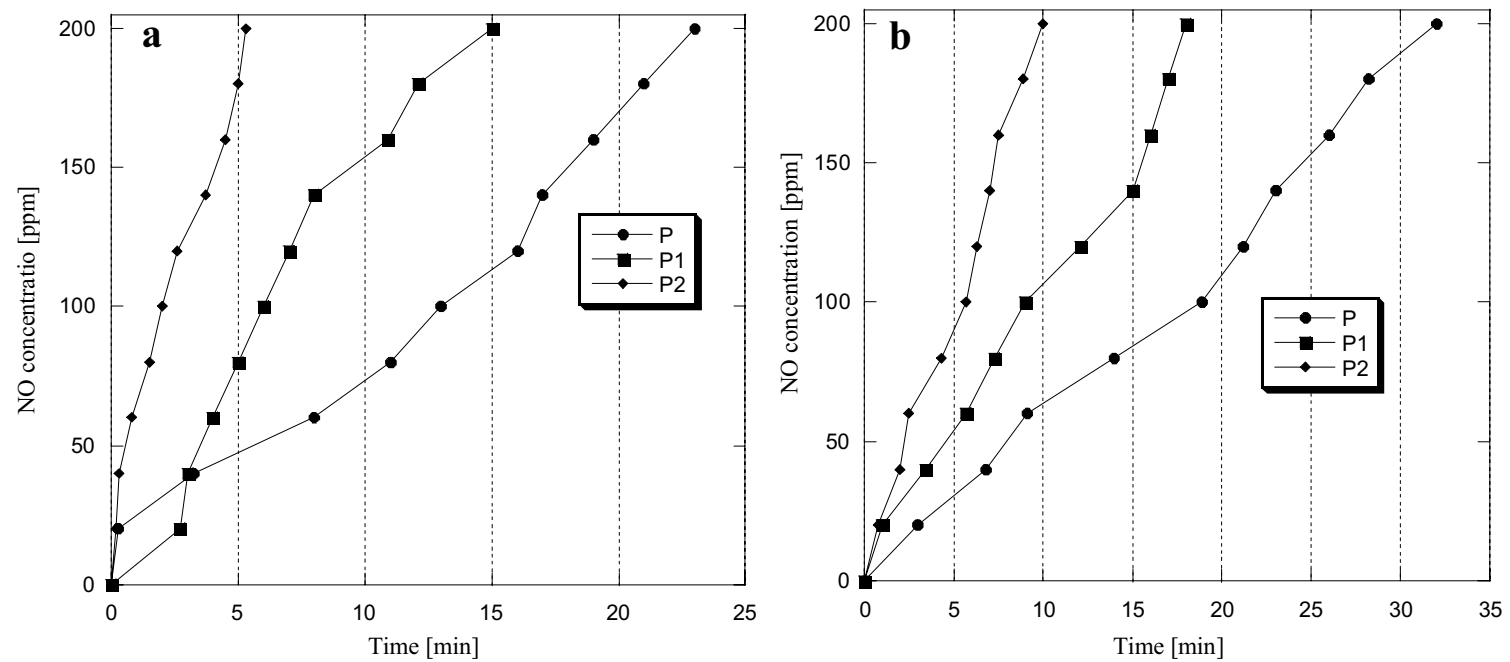

Fig. $5 \mathrm{NO}$ emission curves for the activated bio-carbons obtained during $\mathrm{NO}_{2}$ adsorption in dry (a) and wet (b) conditions

methylene blue by the adsorbents obtained depends first of all on the textural parameters of the bio-carbons. The beneficial effect of washing the activated bio-carbons with $5 \%$ water solution of hydrochloric acid and/ or distilled water on the textural parameters and sorption capacity towards liquid phase pollutants was evidenced. The most effective adsorbent of gas phase pollutant, nitrogen dioxide, was bio-carbon $P$ not subjected to washing. All bio-carbons were more effective in removal of $\mathrm{NO}_{2}$ when the adsorption process took place in wet conditions, which indicates a beneficial effect of steam on the sorption capacity towards $\mathrm{NO}_{2}$. Our results confirmed the beneficial influence of the mineral substance content in the adsorbents on their sorption capacity towards nitrogen dioxide.

Open Access This article is distributed under the terms of the Creative Commons Attribution 4.0 International License (http://creativeco mmons.org/licenses/by/4.0/), which permits unrestricted use, distribution, and reproduction in any medium, provided you give appropriate credit to the original author(s) and the source, provide a link to the Creative Commons license, and indicate if changes were made.

\section{References}

Bashkova, S., Bandosz, T.J.: The effects of urea modification and heat treatment on the process of $\mathrm{NO}_{2}$ removal by wood-based activated carbon. J. Colloid Interface Sci. 333, 97-103 (2009)

Bazan, A., Nowicki, P., Pietrzak, R.: Removal of $\mathrm{NO}_{2}$ by carbonaceous adsorbents obtained from residue after supercritical extraction of marigold. Adsorption 22(4), 465-471 (2016)

Bazan-Wozniak, A., Nowicki, P., Pietrzak, R.: The influence of activation procedure on the physicochemical and sorption properties of activated carbons prepared from pistachio nutshells for removal of $\mathrm{NO}_{2} / \mathrm{H}_{2} \mathrm{~S}$ gases and dyes. J. Clean. Prod. 152, 211-222 (2017)

Benaddi, H., Bandosz, T.J., Jagiello, J., Schwarz, J., Rarzand, A.J., Legras, P., Bequin, F.: Surface functionality and porosity of activated carbons obtained from chemical activation of wood. Carbon 38, 669-674 (2000)

Benedetti, V., Patuzzi, F., Baratieri, M.: Characterization of char from biomass gasification and its similarities with activated carbon in adsorption applications. Appl. Energy 227, 92-99 (2018)

Boehm, H.P.: Some aspects of the surface chemistry of carbon blacks and other carbons. Carbon 32, 759-769 (1994)

Bulut, Y., Baysal, Z.: Removal of $\mathrm{Pb}(\mathrm{II})$ from wastewater using wheat bran. J. Environ. Manage. 78, 107-113 (2006)

Capuzzo, A., Maffei, M.E., Occhipinti, A.: Supercritical fluid extraction of plant flavors and fragrances. Molecules 18, 7194-7238 (2013)

del Valle, J.M.: Extraction of natural compounds using supercritical $\mathrm{CO}_{2}$ : going from the laboratory to the industrial application. J. Supercrit. Fluid. 96, 180-199 (2015)

Georgin, J., Dotto, G.L., Mazutti, M.A., Foletto, E.L.: Preparation of activated carbon from peanut shell by conventional pyrolysis and microwave irradiation-pyrolysis to remove organic dyes from aqueous solutions. J. Environ. Eng. 4(1), 266-275 (2016)

Jones, S., Richardson, N., Bennett, M., Hoon, S.R.: The application of magnetic measurements for the characterization of atmospheric particulate pollution within the airport environment. Sci. Total Environ. 502, 385-390 (2015)

Kazmierczak, J., Nowicki, P., Pietrzak, R.: Sorption properties of activated carbons obtained from corn cobs by chemical and physical activation. Adsorption 19, 273-281 (2013)

Koyuncu, F., Güzel, F., Sayğılıc, H.: Role of optimization parameters in the production of nanoporous carbon from mandarin shells by microwave-assisted chemical activation and utilization as dye adsorbent. Adv. Powder Technol. 29(9), 2108-2118 (2018)

Kulikowska, D., Sułek, P.: Usuwanie zanieczyszczeń organicznych z odcieków składowiskowych metodą adsorpcji na pylistym węglu aktywnym część I. Efektywność procesu (in Polish). Czasopismo Techniczne. Środowisko. 105(1), 89-98 (2008)

Kuramochi, T., Ramírez, A., Turkenburg, W., Faaij, A.: Effect of $\mathrm{CO}_{2}$ capture on the emissions of air pollutants from industrial processes. Int. J. Greenhouse Gas Control 10, 310-328 (2012)

Millao, S., Uquiche, E.: Extraction of oil and carotenoids from pelletized microalgae using supercritical carbon dioxide. J. Supercrit. Fluid 116, 223-231 (2016) 
Nowicki, P., Supłat, M., Przepiórski, J., Pietrzak, R.: $\mathrm{NO}_{2}$ removal on adsorbents obtained by pyrolysis and physical activation of corrugated cardboard. Chem. Eng. J. 195-196, 7-14 (2012)

Nowicki, P., Bazan, A., Kazmierczak-Razna, J., Pietrzak, R.: Sorption properties of carbonaceous adsorbents obtained by pyrolysis and activation of pistachio nut shells. Adsorpt. Sci. Technol. 33(6-8), 581-586 (2015)

Nowicki, P., Kazmierczak-Razna, J., Pietrzak, R.: Physicochemical and adsorption properties of carbonaceous sorbents prepared by activation of tropical fruit skins with potassium carbonate. Mater. Des. 90, 579-585 (2016)

Pallarés, P., González-Cencerrado, A., Arauzo, A.: Production and characterization of activated carbon from barley straw by physical activation with carbon dioxide and steam. Biomass Bioenerg. 115, 64-73 (2018)

Rafatullah, M., Sulaiman, O., Hashim, R., Ahmad, A.: Adsorption of methylene blue on low-cost adsorbents: a review. J. Hazard. Mater. 177, 70-80 (2010) 